\title{
ANÁLISIS SOCIOESPACIAL DE LOS HUMEDALES GUARINÓ Y LA GUINEA (MUNICIPIO DE JAMUNDÍ, COLOMBIA) ${ }^{\mathrm{i}}$
}

Oscar Buitrago BermúdeZ ${ }^{1}$

Marco Antonio Aguirre ${ }^{2}$

\begin{abstract}
RESUMEN - Este estudio busca analizar las formas de producción socio-espacial de dos humedales en el departamento del Valle del Cauca entre mediados del siglo XX y principios del siglo XXI. Tales formas de producción socio-espacial expresan la dialéctica entre los agentes sociales capitalistas - promotores del agro-negocio de la caña de azúcar - y las comunidades locales que resisten la presión ejercida sobre ellas, tanto por estos agentes como por el Estado y sus políticas neoliberales. Para ello, se partió de la teoría de la producción social del espacio de Henri Lefebvre para interpretar la forma particular en que el capitalismo produce el espacio. La investigación integra métodos cualitativos y cuantitativos para comprender la manera en que se ha producido el espacio a lo largo de 50 años en torno a los humedales estudiados. Los resultados se convierten en conocimiento útil y práctico para las comunidades locales, lo cual les permitirá hacer frente a desafíos relacionados con la gestión ambiental, los procesos de resistencia y la conservación de humedales en el departamento del Valle del Cauca.
\end{abstract}

Palabras claves: Espacio; producción social del espacio; humedales.

ABSTRACT - A SOCiO-SPATIAl anAlysis of the Guarinó and Guinea Wetlands (MUNICIPALITy JAMUNDí-ColOMBiA). This study seeks to analyze the socio-spatial production forms of two wetlands in the department of Valle del Cauca between the mid-twentieth and early-twenty first century. Such social-spatial production forms portray the dialectic between the capitalist social agents - promoters of the sugar cane agro-business - and local communities that resist the pressure exerted both by these agents and by the State and its neoliberal policies. To this end, Henri Lefebvre's theory of social production of space is used to interpret the particular way in which capitalism produced space. This research integrates

Recebido: Maio 2016. Aceite: Novembro 2016.

1 Profesor Titular, Universidad del Valle, Departamento de Geografía, Facultad de Humanidades, Cali, Colombia, Calle 13 \# 100 - 00, Edificio 384, Oficina 4002, Teléfono 3212100 Ext. 7088, Dirección de correspondencia: Calle 28 \# 96 - 34 Ap 702 E. E-mail: osbube@yahoo.com

2 Asistente de Investigación, Universidad del Valle, Vicerrectoría de Investigaciones, Cali, Colombia, Calle 13 \# 100 - 00 , Edificio 384, Oficina 4002, Teléfono 3212100 Ext. 7088. E-mail: geografia.777@gmail.com 
qualitative and quantitative methods to understand how space has been produced over 50 years around the wetlands under study. The results offer useful and practical knowledge for the local communities to face the challenges related to environmental management, processes of resistance, and the conservation of wetlands in the department of Valle del Cauca.

Keywords: Space; social production of space; wetlands.

RESUMO - ANALISE SÓcio-espacial dos PANTANAis GUARINó e LA GUINEA (MUNICÍPIO DE JAMUndí, Colombia). Este estudo analisa as formas de produção do espaço social de dois pantanais do sul do departamento do Vale do Cauca na Colômbia, de 1940 ao início do século XXI. Na produção destes espaços expressam-se as contradições entre os agentes sociais capitalistas promotores do agronegócio da cana de açúcar e as comunidades locais que resistem à pressão exercida pelos primeiros e o Estado, o qual, com as suas políticas neoliberais, beneficia os agentes capitalistas. Com base na teoria da produção do espaço de Henry Lefebvre interpretou-se a forma como a sociedade moderna produz o espaço. Para analisar este processo, a pesquisa integrou métodos qualitativos e quantitativos. Os resultados convertem-se em conhecimento útil e prático para as comunidades locais, o qual lhes permitirá fazer frente aos desafios relacionados com a gestão ambiental, os processos de resistência e a conservação dos pantanais no sul do Vale do Cauca.

Palavras-chave: Espaço; produção do espaço social; pantanal.

RÉSUMÉ - Analyse socio-SPaCiale des marais de Guarino ET DE la Guinea (COMmune De JAmind - Colombie). Cette étude analyse les formes de production socio-spaciales de deux marais du Département du Valle del Cauca, depuis les années 1940 jusqu'au début du XXIème siècle. Elles résultent d'une opposition dialectique entre les agents capitalistes producteurs de canne à sucre et les communautés locales, qui ont résisté aux pressions subies de la part de ces entités et de la politique néolibérale de l'Etat colombien. Selon la théorie de production sociale de l'espace, due à Henri Lefebvre, on a analysé ici la façon dont le capitalisme a modelé quantitativement et qualitativement cet espace. Les résultats obtenus doivent permettre aux communautés locales de faire face aux défis de gestion environnementale et de conservation des marais étudiés.

Mots clés: Espace; production sociale de l'espace; zones humides.

\section{I. ¿LA INMINENTE DESAPARICIÓN DE LOS HUMEDALES?}

La producción de caña de azúcar ha estado ligada históricamente al departamento del Valle del Cauca como actividad económica que inició a pequeña escala junto a otras actividades productivas; con respeto a esto, Perafán (2005) y Zuluaga, Valencia \& Arias (2012) describen que para inicios del siglo XX en el Departamento, dichas actividades se caracterizaban "por la presencia de zonas latifundistas y haciendas autosuficientes, con relaciones de mercado débiles, las cuales concentraban la propiedad de las tierras del valle geográfico dedicándolas principalmente a la explotación ganadera y a varios cultivos entre los cuales cabe destacar el café, la caña de azúcar, el arroz, el tabaco, el algodón 
y el maíz" (Perafán, 2005, p. 5). Con este argumento se logra evidenciar para la fecha la presencia del cultivo de caña de azúcar en el Departamento, así como recrear parte del espacio vivido y concebido por determinados agentes sociales.

De la figura 1 se deduce el constante incremento del área sembrada en caña de azúcar para la planicie aluvial del río Cauca a partir de la segunda mitad del siglo XX hasta la primera década del siglo XXI. Es evidente el incremento en hectáreas sembradas las cuales pasaron de 61600 has para el año de 1960, a 225560 has para el año 2013. Es así, como empieza a consolidarse en términos espaciales un complejo económico asociado a la producción de caña que transforma la realidad social, cultural y ambiental, y a manifestarse la lógica de competencias entre unos cuantos actores por el territorio y sus recursos. La expansión de la caña de azúcar como hecho social repercute con mayor fuerza a finales del siglo XX y comienzos del siglo XXI, época en la cual se presenta el auge y crecimiento del desarrollo de la agroindustria en el Territorio Nacional para abastecer en términos energéticos la demanda mundial y nacional por nuevos combustibles basados en el paradigma del desarrollo sustentable y en pro de mejorar las condiciones climáticas a escala global, políticas que se materializaron a través de Planes de Desarrollo de los distintos gobiernos de turno.

ha.

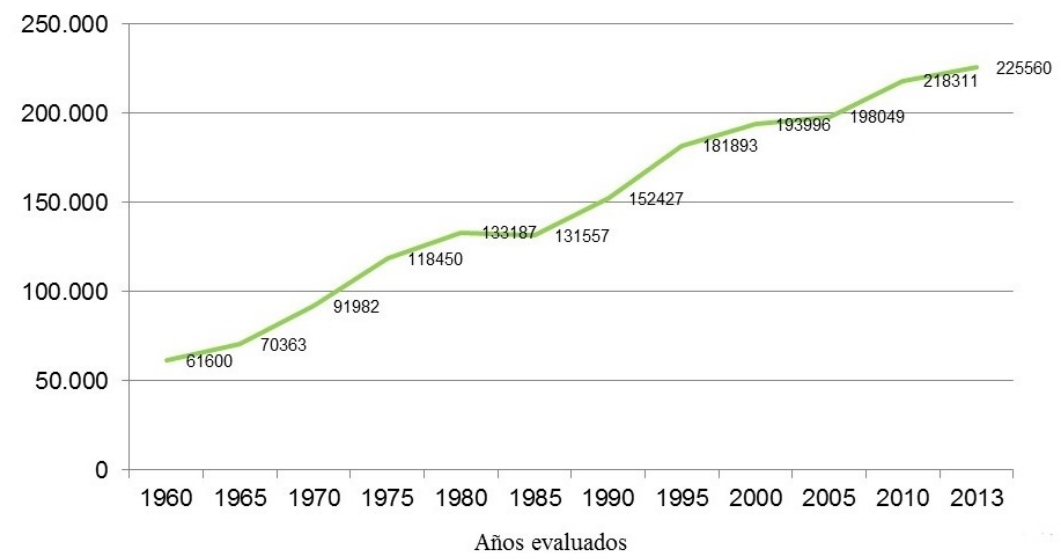

Fig. 1 - Evolución del área sembrada en caña de azúcar sobre la planicie aluvial del río Cauca entre 1960-2013 (Valle del Cauca, Colombia). Imágenes a color disponibles online.

Fig. 1 - Evolution of the area planted in sugar cane on the Cauca River floodplain between 1960-2013 (Valle del Cauca, Colombia). Colour image available online.

Fuente: Elaboración propia a partir de Perafán (2005, p. 9) y la Asociación de Cultivadores de Caña de Azúcar de Colombia (ASOCAÑA) 2014.

Actualmente, la expansión de caña de azúcar como resultado de los intereses de algunos agentes sociales, ha incidido espacialmente sobre buena parte de los ecosistemas localizados en la planicie aluvial del río Cauca donde se encuentran los humedales. Los efectos de dicha actividad se evidencian en las transformaciones del paisaje y el avance o 
retroceso de distintas coberturas (suelo, agua, bosque, espejo lagunar de humedales, etcétera). Los humedales como ecosistemas estratégicos en materia social, ambiental y paisajística, son importantes ya que proveen servicios que contribuyen al bienestar de las comunidades, particularmente aquellas que viven en sus cercanías, ya que estos aportan diversos potenciales de usos como la producción de alimentos (pescado, caza, frutas y granos), purificación del agua, regulación del micro clima y el ciclo hídrico, mitigación del cambio climático y servicios culturales, entre otros aspectos (Ministerio del Medio Ambiente, 2002); además, de ser albergue de gran variedad de fauna y flora y servir de refugio transitorio para aves migratorias. Así mismo, la sociedad se ve directamente afectada cuando no se les da uso adecuado y razonable (Castañeda, 2012, p. 20). Por tal razón, resulta importante interpretar los roles sociales en la producción del espacio para comprender las transformaciones de estos ecosistemas, y contribuir con recomendaciones de uso y manejo.

La figura 2 representa el porcentaje de coberturas evaluadas asociadas a avances y retrocesos en los humedales la Guinea y Guarinó en cuatro años distintos que corresponden a 1943, 1982, 1999 y 2014. Los porcentajes fueron calculados con respecto al área total de estudio para los humedales La Guinea y Guarinó, la cual corresponde a 2 269,22 ha (fig. 2).

El espejo de agua de los humedales evidencia retrocesos en los distintos años considerados. Para el año 2014, La Guinea registró el porcentaje de cobertura más bajo según la figura 2, con un $0,14 \%$ en relación al resto de las coberturas. Las coberturas "Cultivos de Arroz" y "Cultivos Tradicionales" se presentan sólo para los años 1982 y 1999, con incrementos porcentuales para el último año observado, y que posteriormente desaparecen, evidenciando el incremento del monocultivo de la caña de azúcar.

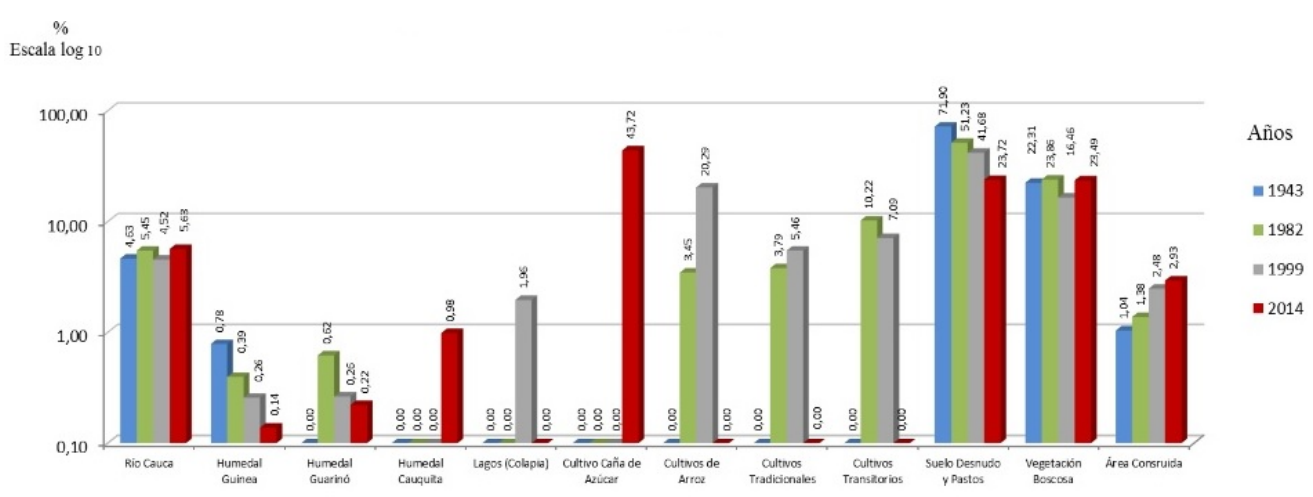

Fig. 2 - Porcentaje de coberturas por año evaluado, humedales Guarinó y La Guinea (Valle del Cauca, Colombia).

Fig. 2 - Percentage of coverages by year evaluated, wetlands Guarinó and La Guinea (Valle del Cauca, Colombia). 
La cobertura "Suelo Desnudo y Pastos" refleja leves descensos en el porcentaje de cobertura según las distintas series evaluadas, salvo el año 2014, que evidencia retroceso de la misma, pasando de 41,68\% en el año 1999 a 23,72\% para el año 2014 . Se resalta que la cobertura asociada a "Vegetación Boscosa" logra mantener constante su área porcentual con respecto al resto de series evaluadas en los distintos años. Finalmente, se observa la manera en la cual el "Área Construida" empieza a crecer progresivamente desde la serie de 1943 con 1,04\% hasta alcanzar un 2,93\% para el año 2014.

\section{PRODUCCIÓN SOCIAL DEL ESPACIO EN LOS HUMEDALES DE ESTUDIO}

Para comprender las formas de producción social del espacio en los humedales se parte de los planteamientos teóricos propuestos por Lefebvre (2013) quien considera el espacio como "producto, productor y soporte de las relaciones económicas y sociales, [...] las fuerzas productivas y la división del trabajo" (Lefebvre, 2013, p. 46). Comprender el espacio conlleva a reconstruir su historia entendiendo para ello "la génisis del espacio y la sociedad actual a través del espacio producido (Lefebvre, 2013, p. 47). Así, el espacio como producción social tiene su propia historia que define las características iniciales de sus dinámicas e interacciones y a través del cual es posible comprender relaciones de poder que configuran los modos de producción socioespacial. Lefebvre (2013) plantea dos interrogantes en términos de la producción social del espacio, el primero con respecto a ¿quién produce? el espacio y el segundo, a ¿cómo se produce el espacio?; además, agrega: "el espacio social se produce y reproduce en contacto con las fuerzas productivas y las relaciones de producción" (Lefebvre, 2013, p. 133) teniendo presente que el espacio resulta del "proceso de múltiples aspectos y movimientos" (2013, p. 164).

Para interpretar y abordar la producción del espacio social, Lefebvre (2013) propone tres momentos de producción espacial a saciados a lo percibido, lo concebido y lo vivido, que corresponden a fases no secuenciales del proceso de producción del espacio social, con lo cual busca interpretar el espacio integrando elementos físicos, mentales y sociales que se encuentra intrincados y se coproducen.

En ese sentido, el espacio percibido se asocia a las prácticas espaciales de la realidad cotidiana materializadas a través de distintos objetos, así por ejemplo, "las grandes ciudades medievales, castillos y catedrales" (Lefebvre, 2013, p. 111) logran transmitir la esencia espacial de lo que una vez fue Europa y de cierta forma, contar elementos de la historia de dichos objetos con respecto a las prácticas sociales que en un tiempo produjeron tal espacio socialmente. En palabras de Lefebvre (2013, p. 97) "la práctica espacial de una sociedad secreta su espacio; lo postula y lo supone en una interacción dialéctica; lo produce lenta y serenamente dominándolo y apropiándose de él. Desde el punto de vista analítico, la práctica espacial de una sociedad se descubre al descifrar su espacio".

Esta perspectiva fue asumida por Soja (2000) quien define el espacio percibido "como un complejo de prácticas espaciales materializadas, que trabajan en forma conjunta para producir y reproducir las formas concretas y los patrones específicos [...] como forma de 
vida" (Soja, 2000, p. 39), es decir, todos los elementos físicos y prácticas sociales que definen determinado espacio y que pueden ser cuantificables, así como expresarse a través del mapa. Esta forma de entender la producción del espacio reinó por mucho tiempo en los estudios de interpretación de las ciudades desde posturas objetivas que resaltaban las "cosas en el espacio" (2000, p. 40), es decir, todos los elementos que lograron materializarse y componen la ciudad. La caña de azúcar, por ejemplo, se interpreta como aquella práctica espacial materializada a lo largo del valle geográfico del río Cauca por distintos agentes capitalistas, que de cierta forma ha logrado incidir en las dialécticas sociales y modos de vida tradicionales de las comunidades que por décadas han vivido y habitado los humedales. De esta forma, las prácticas espaciales (modos de vida, prácticas culturales, etc.) de las comunidades en los humedales se ha visto alterada por la materialización de la caña de azúcar en el tiempo.

El espacio concebido desde la triada de Lefebvre (2013) se construye a partir de los ideales colectivos o individuales, el querer ser, así, como todo lo que se define desde la norma. Dicha forma de producción del espacio se encuentra permeada según intereses, posturas políticas, culturales y filosóficas. Aquel espacio es producido por "científicos, planificadores, urbanistas, tecnócratas fragmentadores, ingenieros sociales [...] los cuales identifican lo vivido y lo percibido con lo concebido" (Lefebvre, 2013, p. 97). Es sin dudas el "espacio dominante en cualquier sociedad o modo de producción" (2013, p. 97). Este espacio se representa a través de signos verbales que logran ser materializados a través de normas, decretos, leyes y políticas de gobierno. La comprensión e interpretación del espacio percibido es de carácter subjetivo puesto que tiende a "ocuparse de las reflexiones acerca del espacio" (Soja, 2000, p. 40). En palabras de Soja (2000), el espacio concebido es "conceptualizado en imágenes, pensamientos reflexivos y representaciones simbólicas, un espacio concebido por la imaginación, o aquello que en lo sucesivo describiré como el imaginario" (2000, p. 39).

Con lo anterior, el espacio concebido se interpreta como la ruta a seguir para la realización de determinadas acciones en el tiempo, por ejemplo, el hecho de que existan políticas de desarrollo a nivel nacional que propicien la expansión de agricultura de negocio a gran escala, podría interpretarse como aquella forma de producción espacial sustentada en los intereses colectivos de unos pocos agentes sociales que conciben, en la expansión agrícola, el desarrollo de un país; o las políticas de orden internacional, como la declaración de RAMSAR ${ }^{\mathrm{ii}}$ (2013), en la cual los humedales se conciben como áreas estratégicas para la conservación de la biodiversidad que albergan (Secretaría de la Convención de Ramsar, 2013). En ese contexto, resulta importante comprender y reflexionar de manera crítica acerca de cómo las prácticas de concepción de los espacios a partir de la norma, la planificación o políticas de desarrollo, han incidido en el estado actual de los humedales y en el desarrollo de actividades de comunidades.

El espacio vivido corresponde al espacio de las representaciones colectivas e individuales, en el cual se incorporan los espacios percibidos y concebidos. "Se trata del espacio dominado, esto es, pasivamente experimentado, que la imaginación desea modificar y tomar. Recubre el espacio físico utilizando simbólicamente sus objetos" (Lefebvre, 2013, 
p. 98). En palabras de Soja (2000, p. 40), se trata de "un lugar simultáneamente real e imaginario, actual y virtual, lugar de experiencia". Esta forma de comprender e interpretar la producción social del espacio se asocia según Soja (2000, p. 40) al acto de "escribir una biografía [...] es decir, al intento de describir y entender el tiempo vivido de las colectividades o las sociedades humanas". Es importante aclarar que obtener la totalidad de las experiencias vividas resulta imposible, "[...] hay demasiadas cosas, desconocidas y tal vez incognoscibles, que yacen debajo de la superficie como para que sea posible contar una historia completa" (2000, p. 41).

En relación al espacio vivido, Bhabha (1996) desde la teoría post-colonialista se refiere a él como el tercer espacio o espacio de la presencia, en el cual "la diferencia histórica del presente es articulada en la emergencia de un tercer espacio de representación que es, de inmediato, reabsorbida en la división base-superestructura" (Bhabha, 1996, p. 266) a través de narrativas. En palabras de Ashcroft (Ashcroft 1995 citado en Hernando, 2004, p. 113) el tercer espacio se remite al clásico modelo "de la baranda, es decir, a un espacio arquitectónico, lugar entre el adentro y el afuera, el hogar y el mundo, lo nuestro y lo otro". En otras palabras, la baranda se refiere al puente conector entre el pasado y el presente desde el cual es posible extraer la biografía de distintos sucesos y acciones colectivas que dan cuenta de cómo fueron tales acontecimientos en la vida de las personas, [...] de esta forma, se constituye $e$ interpreta el Tercer Espacio, que es el mismo al que alude Bhabha" (Hernando, 2004, p. 113). A partir del espacio vivido es posible identificar y comprender elementos en el tiempo asociados a conflictos, sean estos por el agua de los humedales, usos del suelo, conflictos socioambientales, y a elementos vinculados con prácticas culturales como festividades, rituales, etc.

\section{METODOLOGÍA GENERAL}

Para llevar a cabo esta investigación, se integró información cualitativa recabada a partir de trabajo de campo con agentes sociales bajo la modalidad de talleres y entrevistas, que permitieron identificar las distintas fases de producción socioespacial (espacio percibido, concebido y vivido), con información cuantitativa obtenida de la elaboración de mapas dinámicos para los años 1943, 1982, 1999 y 2014, empleando para ello aerofotografías e imágenes de satélite.

Para realizar estos procesos metodológicos fue necesario definir un área de estudio, la cual se estableció a partir de tres criterios geográficos: el primero, asociado a referentes físicos como colinas, lomeríos y planicies, pendiente del terreno, la planicie aluvial del río Cauca y curvas de nivel; el segundo criterio, basado en aspectos hidrológicos tales como la cuenca hidrográfica donde se localizan los humedales y su respectiva red hídrica; en el tercer criterio está la localización de elementos funcionales como vías, poblados, carreteras y caminos, áreas construidas y canales colectores de agua superficial observados en fotografías aéreas, imágenes de satélite y trabajo en campo. Dichos mapas permitieron corroborar elementos de la fase de producción social del espacio 
percibido, puesto que a través de ellos, se identificó cambios en las coberturas (espejo de agua laminar, vegetación boscosa, suelo desnudo y pastos, cultivos transitorios y permanentes); además, se calculó tasas de pérdida y retroceso en área para las coberturas en los distintos años avaluados. En las figuras 3 y 4 se observa parte del trabajo en campo con las comunidades.

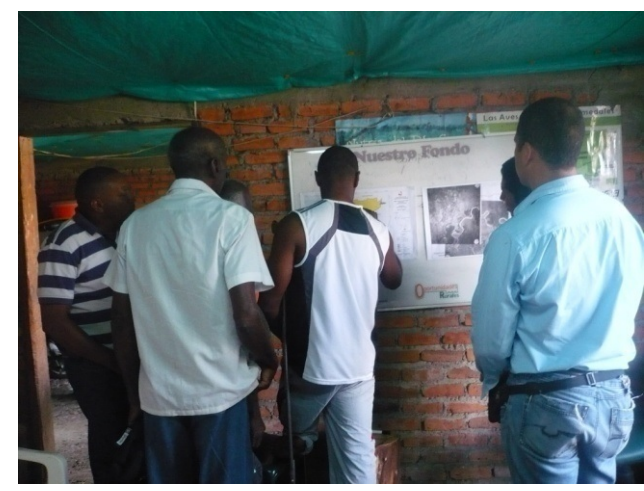

Fig. 3 - Trabajo en campo con agentes sociales

(Municipio de Jamundí, Colombia). Imágenes a color disponibles online.

Fig. 3 - Field work with communities (Municipality de Jamundí, Colombia). Colour figure available online.

Fuente: Aguirre \& Perdómo (2015, p. 33)

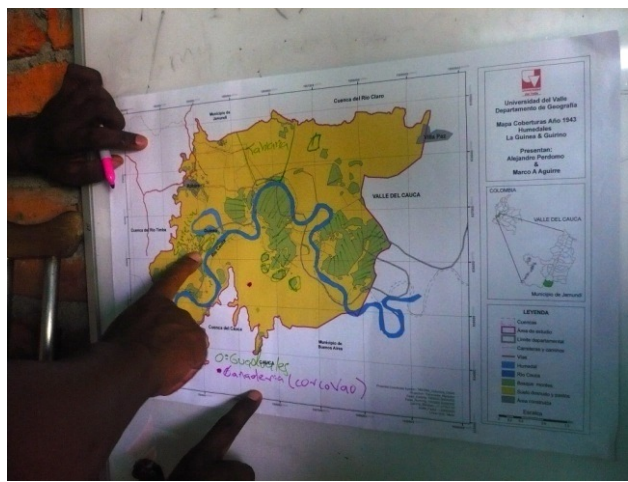

Fig. 4 - Validación de coberturas (Municipio de Jamundí, Colombia). Imágenes a color disponibles online.

Fig. 4 - Validation of coverages (Municipality de Jamundí, Colombia).

Colour figure available online.

Fuente: Aguirre \& Perdómo (2015, p. 33)

El espacio percibido se interpretó a partir de la realización de entrevistas semiestructuradas, talleres con agentes sociales y el empleo de cartografía asociada al cambio de coberturas para cada año evaluado. Esta fase permitió identificar cómo las distintas prácticas materiales promovidas por agentes capitalistas incidieron en la transformación de los humedales y las actividades cotidianas de los pobladores.

Para interpretar el espacio concebido, se tuvo en cuenta elementos normativos como Planes de Manejo Ambiental de Humedales, Políticas del orden Nacional e Internacional, Acuerdos, etc., y la forma en que las comunidades y agentes sociales han planificado el uso y manejo en estos ecosistemas en el tiempo. En ese sentido, se llevó a cabo todo un recorrido de la normativa asociada a los humedales a nivel Local, Nacional e Internacional; la revisión se trianguló con los relatos registrados a través de entrevistas.

Para comprender los espacios vividos se tiene presente aspectos asociados a conflictos suscitados por el agua de los humedales, uso del suelo, acceso, uso del humedal, estado socioambiental, y prácticas culturales en torno a estos ecosistemas como festividades y rituales. Para ello, se empleó la información suministrada a través de las entrevistas semiestructuradas y el desarrollo de talleres. 


\section{DESCRIPCIÓN GENERAL DE LOS HUMEDALES LA GUINEA Y GUARINÓ}

Los humedales estudiados corresponden a las madreviejas La Guinea y Guarinó localizadas al sur del municipio de Jamundí, en jurisdicción de los corregimientos de Robles, Quinamayo Villa Paz (fig. 5). La Guinea pertenece a la cuenca del río Timba, la cual posee un área de captación de 441,6 ha., su altura de 978 m.s.n.m. La Madrevieja Guarinó pertenece a la cuenca del río Claro, con una altura de 970 m.s.n.m.; su área de captación es de 152,9 ha., aproximadamente; ambos humedales se localizan en la margen izquierda del río Cauca en sentido sur - norte (Corporación Autónoma Regional del Valle del Cauca, 2009, p. 69). La Guinea es un humedal natural lentico lacustre y Guarinó, un humedal lentico palustre (figs. 6 y 7). Los corregimientos donde se localizan los humedales tienen una población de 12000 habitantes distribuidos en los corregimientos de Robles, Quinamayo y Villa Paz, siendo Quinamayo el de mayor concentración de población con 5500 habitantes (Corporación Autónoma Regional del Valle del Cauca, 2011, p. 189).

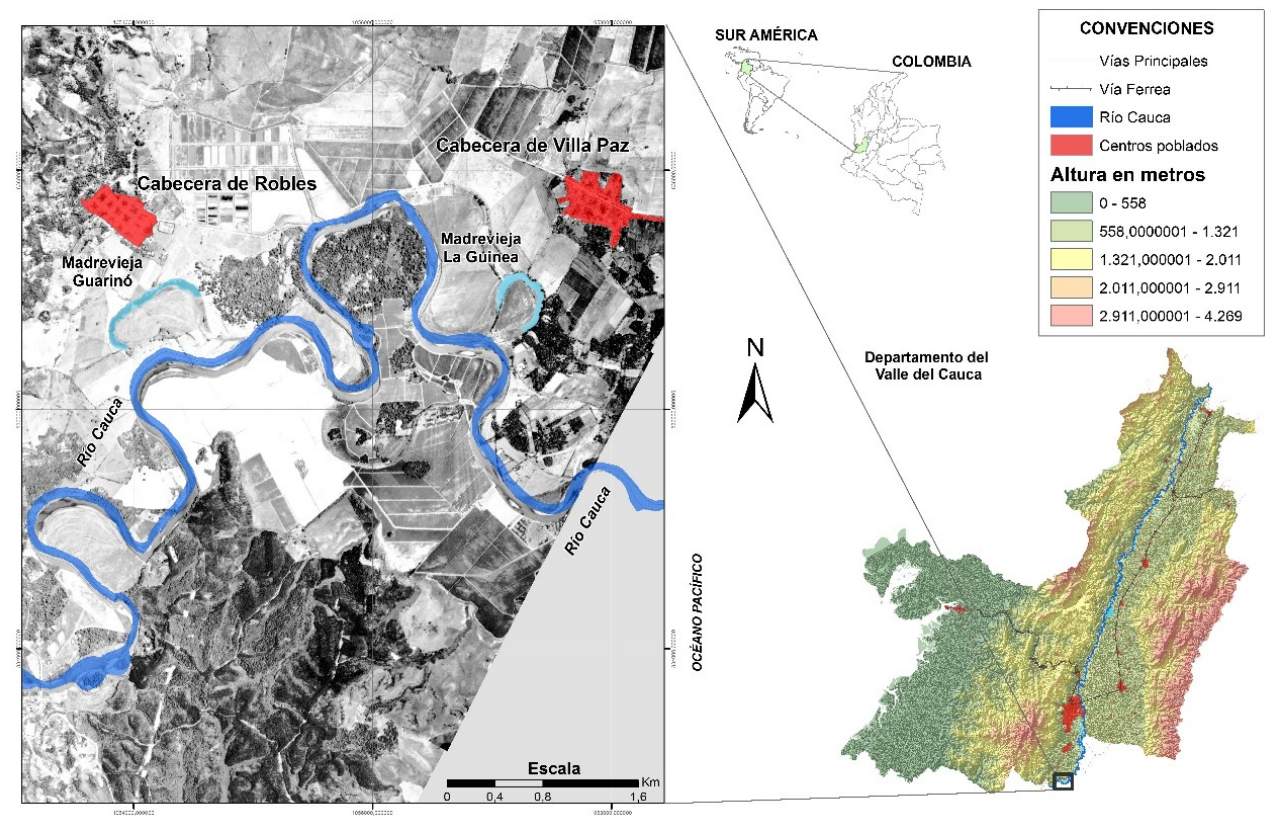

Fig. 5 - Localización humedales de estudio: Madreviejas La Guinea y Guarinó (municipio de Jamundí, Colombia). Imágenes a color disponibles online.

Fig. 5 - Location wetlands study: madreviejas La Guinea and Guarinó (municipality de Jamundí, Colombia). Colour figure available online.

Fuente: Fotomosaico aerofotografías FAL $407-42^{\mathrm{a}}-158$, 159. Elaboración propia a partir de cartografía base suministrada por Corporación Autónoma Regional del Valle del Cauca (CVC) 


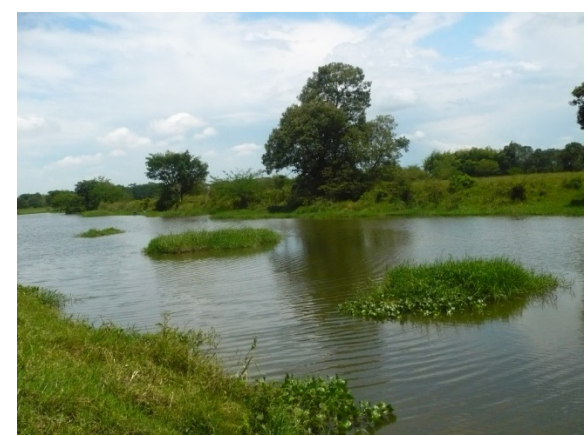

Fig. 6 - Humedal La Guinea (municipio de Jamundí, Colombia). Imágenes a color disponibles online.

Fig. 6 - Wetland The Guinea (municipality de Jamundí, Colombia).

Colour figure available online.

Fuente: Aguirre \& Perdomo (2015, p. 58)

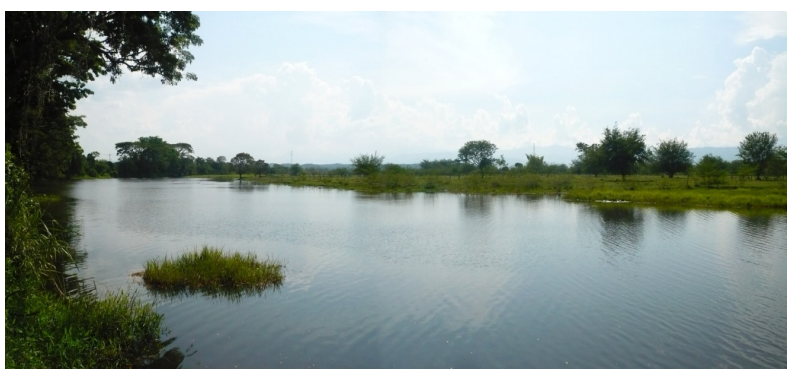

Fig. 7 - Humedal Guarinó (municipio de Jamundí, Colombia). Imágenes a color disponibles online.

Fig. 7 - Wetland Guarinó (municipality de Jamundí, Colombia).

Colour figure available online. Fuente: Aguirre \& Perdomo (2015, p. 59)

Etnográficamente se presenta mestizaje con predominio de población afrodescendiente procedente del norte del departamento del Cauca, quienes históricamente han estado ligados a estos territorios a partir de procesos de asentamientos que datan de finales del siglo XVIII, como resultado de las postrimerías de la esclavitud. Buena parte de las tierras ocupadas hoy en día, fueron adquiridas a terratenientes de la región, las cuales se pagaron con labores domésticas y agrícolas por los primeros grupos asentados. Históricamente, el uso del suelo ha estado ligado a prácticas agropecuarias sustentadas en la ganadería extensiva a pequeña escala, siembra de cultivos transitorios como maíz, millo y arroz, y hacia el fomento de agricultura pancoger (cultivos de subsistencia) en fincas tradicionales. Actualmente, el área de los humedales se encuentra amenazada por la concepción capitalista de agentes sociales quienes han propiciado la expansión de la agricultura de negocio sustentada en el monocultivo de la caña de azúcar.

\section{RESULTADOS}

Los resultados se presentan en tres apartados que corresponden primero, a los espacios percibidos, segundo, a los espacios concebidos, y finalmente, a los espacios representativos o vividos.

\section{Espacios percibidos}

Con respecto al espacio percibido, los agentes entrevistados en los talleres coincidieron en aspectos asociados a prácticas materiales que tradicionalmente se han desarrollado cerca los humedales, el papel de algunas coberturas naturales, y actividades productivas que paulatinamente fueron impuestas por distintos agentes sociales. Con 
respecto a lo anterior, se resalta la agricultura de subsistencia, la cual se efectuaba en la finca tradicional como forma de integrar elementos asociados al agua de los humedales, bosques protectores, las dinámicas naturales del río Cauca y la producción de cultivos de pancoger; todo esto con el fin de garantizar la seguridad alimentaria de las comunidades locales, y mitigando de esta forma, los efectos ambientales de dichas prácticas con el medio natural y los humedales. Además, se destaca la pesca artesanal realizada en fechas específicas bajo criterios sacros, producto de la herencia cultural de estos pueblos afrodescendientes, como práctica que fomentaba el uso racional de peces, permitiendo los procesos naturales de reproducción y restauración de los mismos. Entre las prácticas productivas potenciadas por agentes capitalistas se destacan la ganadería extensiva, el cultivo de arroz y el monocultivo de caña de azúcar, este último, como actividad que según los agentes entrevistados ha inducido en las mayores transformaciones del paisaje de los humedales, y afectando la disposición de suelos, agua, y fauna y flora.

Ejemplo de lo anterior es la cobertura asociada a "Vegetación Boscosa" identificada como bosques protectores que por años ha estado vinculada a los humedales sirviendo de soporte al desarrollo de actividades agropecuarias, como la pesca artesanal, y en la consolidación y permanencia de la finca tradicional. Esta cobertura resulta importante puesto que se considera esencial por los agentes entrevistados en la articulación río finca tradicional - humedales, y que actualmente ha empezado a desaparecer dando paso a la expansión de la caña de azúcar.

En palabras de uno de los agentes sociales entrevistados se evidencia parte de la materialización de algunas prácticas socioespaciales establecidas para la década de 1930 y el tipo de paisaje en ese entonces:

“[...] bueno, mi abuela me contaba más o menos de 1930 sobre cómo estaba el humedal de Cucho de Yegua y el humedal de acá, de La Guinea, que son los más viejos. Nos decía, que todos esos humedales tenían sus bosques protectores; [...] en ese tiempo las áreas de cultivos transitorios y potreros eran muy pequeñas, el resto era o bosque o finca tradicional, un bosque productivo; eso era el entorno de esos ecosistemas que estaban conectados al río en los canales de entrada y salida de agua a los humedales." (Entrevista agente social, Corregimiento de Quinamayó, 2014).

La figura 8 evidencia la distribución espacial de la cobertura "Vegetación Boscosa" alrededor del río Cauca y los humedales, además de la relación que se menciona por parte del agente social en términos de la triada río-humedal-finca tradicional (fig. 8). En el cuadro I se puede observar como la tasa de cambio porcentual del área de esta cobertura presenta leves fluctuaciones en los años evaluados, pasando de 506,27 ha en el año base de 1943 a 541,44 ha para 1982; este incremento de la cobertura coincide con el fomento de políticas de conservación en el área de los humedales. Para el año de 1999 se presenta la mayor pérdida de esta cobertura, registrando 373,44 ha, es decir, un porcentaje de cambio negativo de $-31,04 \%$ con respecto al año base anterior a la fecha de 1982, cambios que se produjeron por la expansión de cultivos transitorios y ganadería extensiva. Entre 1999 y 2014, se produjo un incremento de la misma cobertura con una tasa porcentual positiva de $42,77 \%$ con respecto al año base de 1999, sin embargo, en la figura 8 se 
observa espacialmente la fragmentación constante de esta cobertura en el tiempo. En palabras de otro de los agentes entrevistados, se menciona lo siguiente:

"Las áreas protectoras no eran, ni caña ni pasto, ninguna de esas cosas, sino que había una serie de bosque; por ejemplo mucho guayabo, frutales, mango, Nacedero, Matarratón. Entonces, todo eso protegía la avifauna [...] también, había, cierto tipo de pastos, pastos no para ganado, sino malezas que conservaban los suelos." (Entrevista agente social, Corregimiento de Quinamayó, 2014).

Este argumento ratifica la importancia de los bosques como elementos protectores de distintas especies en función de los humedales y la finca tradicional, a pesar de que el área de estudio se ha caracterizado por grandes extensiones de pastos naturales con presencia de ganadería a pequeña escala. Según los agentes entrevistados, para la década de 1980 se perciben algunas transformaciones importantes en el paisaje de los humedales, puesto que se produjo mayor diversificación de coberturas asociadas a cambios en el uso del suelo, que según ellos, atentó directamente con las áreas provistas de bosques protectores y pastos naturales, esto, asociado a la llegada de agentes capitalistas quienes empezaron a comprar terrenos y grandes fincas acondicionándolas para el desarrollo de prácticas agropecuarias tales como ganadería extensiva, cultivos de maíz y arroz, y fomentando actividades de piscicultura. En la figura 8, se observan dichos cambios. A continuación, se presenta un fragmento de las entrevistas realizadas a uno de los agentes sociales del área de estudio:

"Es para 1980 cuando en esta zona aparece el boom de los narcos, y empiezan a comprarle tierra a todo el mundo y a meter ganado, a hacer potrero donde se sembraba arroz acabando con algunos bosquecitos." (Entrevista agente social, Corregimiento de Villa Paz, 2014).

Cuadro I - Tasa de cambio porcentual por coberturas, humedales La Guinea y Guarinóiii.

Table I - Percentage change rate hedges, wetlands La Guinea and Guarinó.

\begin{tabular}{|c|c|c|c|c|c|c|c|}
\hline \multirow{2}{*}{ Coberturas } & \multicolumn{4}{|c|}{ Total Áreas ha / año } & \multirow{2}{*}{$\begin{array}{c}\text { \% de cambio } \\
1943-1982\end{array}$} & \multirow{2}{*}{$\begin{array}{c}\text { \% de cambio } \\
1982-1999 \\
\end{array}$} & \multirow{2}{*}{$\begin{array}{c}\% \text { de cambio } \\
1999-2014\end{array}$} \\
\hline & 1943 & 1982 & 1999 & 2014 & & & \\
\hline Río Cauca & 105,02 & 123,77 & 102,49 & 127,86 & 17,85 & $-17,19$ & 24,76 \\
\hline Humedal Guinea & 17,76 & 8,96 & 5,83 & 3,13 & $-49,55$ & $-34,97$ & $-46,23$ \\
\hline Humedal Guarinó & 0,00 & 14,04 & 5,96 & 5,01 & * & $-57,55$ & $-15,90$ \\
\hline Humedal Cauquita & 0,00 & 0,00 & 0,00 & 22,31 & * & * & 0,00 \\
\hline Lagos (Colapia) & 0,00 & 0,00 & 44,40 & 0,00 & * & * & $-100,00$ \\
\hline Cultivo Caña de Azúcar & 0,00 & 0,00 & 0,00 & 992,09 & * & * & 0,00 \\
\hline Cultivos de Arroz & 0,00 & 78,32 & 460,46 & 0,00 & * & 487,96 & $-100,00$ \\
\hline Cultivos Tradicionales & 0,00 & 85,98 & 123,99 & 0,00 & * & 44,21 & $-100,00$ \\
\hline Cultivos Transitorios & 0,00 & 232,02 & 161,00 & 0,00 & * & $-30,61$ & $-100,00$ \\
\hline Suelo Desnudo y Pastos & $1.631,68$ & $1.162,51$ & 945,83 & 538,29 & $-28,75$ & $-18,64$ & $-43,09$ \\
\hline Vegetación Boscosa & 506,27 & 541,50 & 373,44 & 533,16 & 6,96 & $-31,04$ & 42,77 \\
\hline Área Construida & 23,51 & 31,262 & 56,20 & 66,53 & 32,96 & 79,78 & 18,38 \\
\hline
\end{tabular}


Afínales del siglo XX se evidencian las mayores transformaciones en el paisaje de los humedales con la llegada del monocultivo de la caña de azúcar, práctica material desarrollada y propiciada por agentes capitalistas quienes encuentran en dichas tierras la oportunidad de expandir sus agronegocios, auspiciados por políticas de los gobiernos de turno las cuales fomentaban tales prácticas. Según los agentes sociales entrevistados, desde el año 1990 se observaba la adecuación de tierras alrededor del área de estudio para la implementación de estos cultivos. Esta información se logra evidenciar a partir de los datos presentes en el cuadro I, en la medida que coberturas como "Cultivos Tradicionales" y "Cultivos Transitorios" pierden área con respecto a los años entre 1999 y 2014, dando paso espacialmente a la expansión del monocultivo de la caña de azúcar, la cual registró un área total de 992,09 ha en relación al área de estudio (2 269,22 ha), es decir, que la caña ocupó cerca del $43,17 \%$ del área total (cuadro I).

$\mathrm{Al}$ observar la figura 8 se evidencia la forma en que se configura el paisaje de los humedales de modo tal, que para el año 2014 se tiene un paisaje que responde a los intereses de agentes capitalistas a través del monocultivo de la caña de azúcar, reflejando toda una lógica de producción cuya materialización es percibida a través del paisaje, propio del agronegocio de la caña, el cual ha dejado rezagadas prácticas socioespaciales importantes para las comunidades que por décadas han producido dichos espacios intentando un equilibrio entre sus actividades de sustento y los ecosistemas.

La madre vieja La Guinea es el humedal con la mayor pérdida en área de espejo lagunar para los distintos años, pasando de 17,76 ha, en 1943 a representar 3,13 ha, para el año 2014 (cuadro I). La mayor tasa de cambio porcentual de este humedal se registró entre el periodo comprendido por los años 1943 y 1982, fechas que concuerdan con la adquisición de tierras por agentes capitalistas para la expansión de la frontera agrícola y actividades de ganadería extensiva. Por el contrario, La madrevieja Guarinó evidencia retrocesos en su cobertura siendo la mayor tasa de pérdida porcentual en área, la registrada para el periodo comprendido entre 1982 y 1999, pasando de 14,04 ha, en el año base de 1982 a 5,96 ha, para 1999.

\section{Espacios concebidos: el papel de la planificación social, los agentes capitalistas y el Estado}

Históricamente la planificación y las formas de concebir el espacio, por los distintos agentes sociales de los humedales del Sur del municipio de Jamundí, han estado ligadas a tres aspectos, cada uno de ellos respondiendo a intereses sociales particulares. El primero, promovido por agentes capitalistas, sustentado en la producción económica a partir de actividades agropecuarias a gran escala tales como: ganadería extensiva y en la siembra de caña de azúcar. Esta forma de concebir el espacio logró materializarse desde la concepción de desarrollo incorporada en el Departamento a mediados del siglo XX por las élites de la región quienes veían en el valle geográfico del río Cauca oportunidades para el crecimiento económico capitalista. En dicha visión de desarrollo, era necesario regular las frecuentes inundaciones del río Cauca, dando paso a 


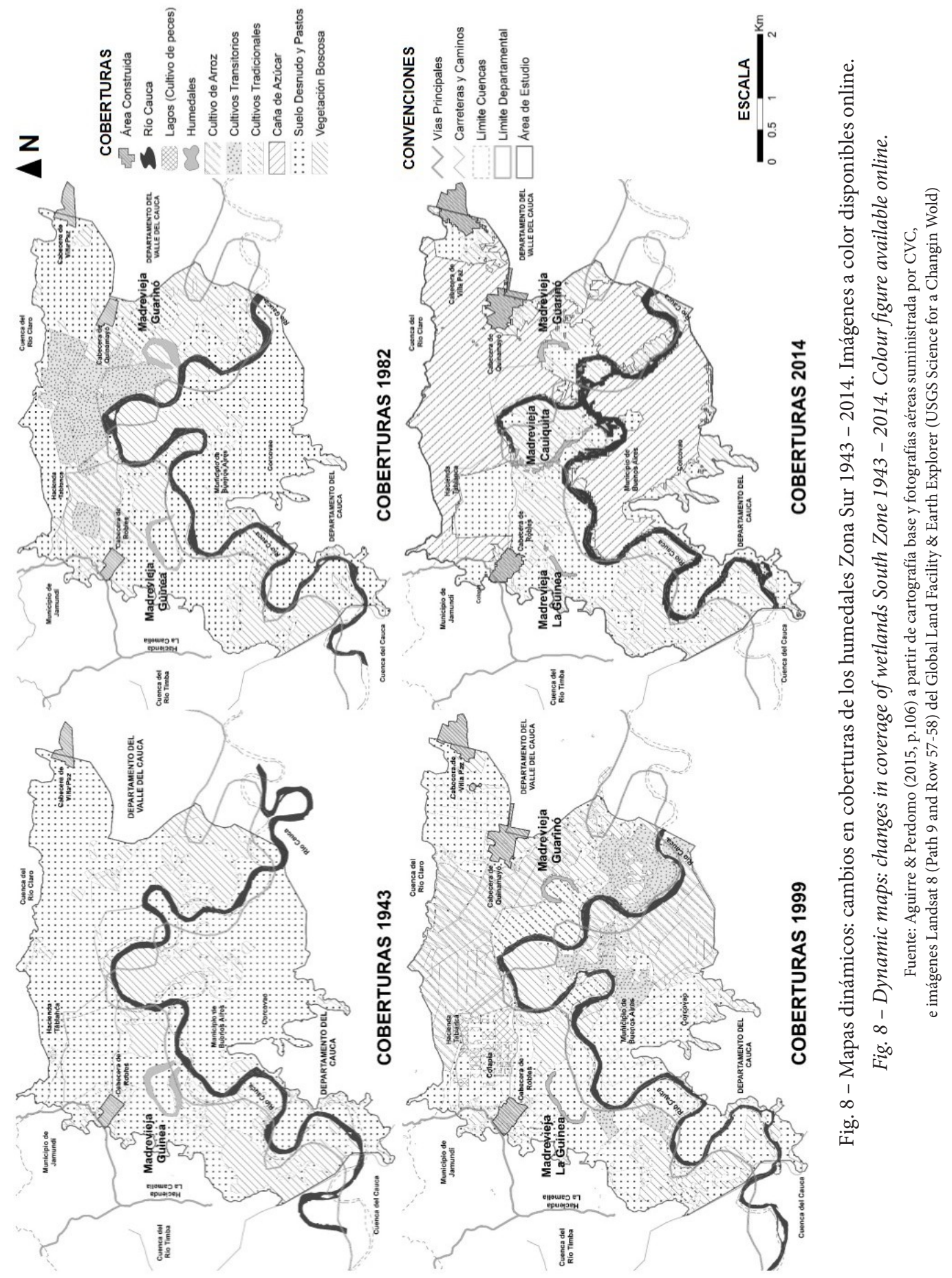


procesos de adecuación de tierras para la implementación de actividades agropecuarias a gran escala. En esta fase de producción social del espacio los humedales y otros ecosistemas representativos del valle geográfico del río Cauca se veían como obstáculos a la consecución de tales objetivos.

El segundo aspecto, asociado a las formas de concebir los humedales por las comunidades locales, propias del área de estudio, que por décadas han hecho uso de estos ecosistemas. En ese sentido, los agentes entrevistados comentan que sus formas de concebir los humedales gira en torno a las formas de organización de las comunidades frente a procesos de planificación y toma de decisiones, que incluyen a las madreviejas como sus referentes de vital interés, al corto y largo plazo, pues de ellas depende buena parte de sus actividades cotidianas, de subsistencia y esparcimiento; dichas formas de concebir el espacio se han materializado a través de organizaciones como FUNECOROBLES iv , Asociación de Carabineros de Villa Paz, Fundación Ambiental Palenque Cinco, Corpovillapaz, instituciones educativas, y a través de la participación activa de $\mathrm{ONG}^{\prime}$ 's de carácter ambiental interesadas por el tema de los humedales.

Tercero, el rol que ha jugado la planificación concebida por agentes institucionales en representación del Estado, quienes son los encargados de materializar las distintas políticas internaciones (Ramsar, 2013) y locales (Política Nacional para Humedales Interiores de Colombia, 2002) frente a los humedales, y cuya materialización en el tiempo ha contribuido de manera directa en los cambios asociados al paisaje de dichos ecosistemas. Esta forma de concebir el espacio ha dejado consecuencias positivas para unos cuantos agentes sociales, y estragos en otros grupos. Tal es el caso de los industriales, quienes han encontrado oportunidades de negocio a través del fomento de políticas desarrollistas asociadas a la expansión de la frontera agrícola en región, logrando de esta forma, escenificar en materia espacial, el crecimiento del monocultivo de caña de azúcar. Por el contrario, hay quienes ven en las distintas políticas desarrollistas obstáculos para la conservación y oportunidades para la gestión de los ecosistemas.

Desde esta postura, se crean mecanismos que pretenden proteger los ecosistemas y reivindicarlos como elementos públicos y, por otro, se busca la forma de privatizar y eliminar los humedales en aras de la expansión del agronegocio mediante políticas desarrollistas de los distintos gobiernos. Al final, las múltiples formas de concebir el espacio logran materializarse en el tiempo a través del paisaje de los humedales con beneficios para unos pocos y pérdidas para otros.

Entre las formas de concepción del espacio por parte el Estado, se resalta el rol de la propiedad privada como elemento que ha incidido en la gestión y planificación de humedales, ya que estos ecosistemas se han localizado en propiedad privada. Dicha ambivalencia ha generado malestar social y conflictos entre las personas que intentan concebir herramientas de conservación y materializar acciones en pro de los humedales y los dueños de los respectivos predios donde se localizan los humedales. Con respecto a lo anterior, la Constitución colombiana de 1991 garantiza tanto la 
propiedad privada como los bienes públicos, razón por la cual muchos de los procesos se ven entorpecidos, incluyendo las funciones de agentes institucionales como la Corporación Autónoma Regional del Valle del Cauca (CVC) en su actuar como autoridad competente frente a la protección y vigilancia de humedales. En relación a las formas de concebir el espacio social, los agentes entrevistados resaltan que para el año 2000 se construyó el primer Plan de Manejo del humedal Guarinó como alternativa para mejorar las condiciones ambientales del humedal. En el año 2006 se actualizó dicho Plan de Manejo con iniciativa de organizaciones locales y el acompañamiento institucional por parte de CVC. En palabras de uno de los agentes entrevistados se observa lo siguiente:

\begin{abstract}
“[...] sí, como en el año 2000 se hizo el primer Plan de Manejo, ese Plan de Manejo para esa época, digamos que no era la maravilla, pero era un Plan que le permitía hacer intervenciones importantes en el humedal y mejorar sus condiciones. Luego vino Funecorobles e hizo el de La Guinea, y ese es un Plan de Manejo que lo hacen las organizaciones de acá de la zona en cabeza de Funecorobles, quien presenta el proyecto, pero ahí participa Palenque Cinco, los agricultores, la comunidad educativa, los estudiantes, los padres de familia, niños, las madres cabeza de familia, y la organización de Villa Paz que era Corpovillapaz; entonces se forma un Plan más participativo y mucho más incluyente en cuanto a la visión de la gente de cómo debería ser el humedal. Desafortunadamente ese Plan de Manejo que era a diez años se quedó en eso [...]." (Entrevista agente social, Corregimiento de Quinamayó, 2014).
\end{abstract}

De esta forma, la comunidad, organizaciones locales y ONG's incorporaron en el Plan de Manejo una visión de carácter social y participativa, que hacen del humedal un hecho de construcción social concibiéndolo como elemento que perdure en el tiempo, además de entender y plantear estos ecosistemas como el complejo de humedales del Alto Cauca, los cuales se deben planificar en conjunto y no como simples elementos aislados y fragmentados en el espacio. Aunque el agente social en este argumento resalta la importancia del nuevo Plan de Manejo, también agrega que desafortunadamente este Plan no logró tener el impacto propuesto en el marco de dicho documento.

A demás, se resalta por parte de los agentes entrevistados, que anteriormente, la forma de concebir los humedales se sustentaba desde el arraigo cultural heredado de los primeros pobladores, ya que la visión sacra del agua era trascendental en las decisiones que se tomaban frente a las prácticas de subsistencia sustentadas a través de la finca tradicional; legado que logra materializarse a través de la cobertura asociada a "Vegetación Boscosa" (fig. 8) pues representa el corredor entre el río, los humedales y las actividades productivas. Entre las formas de concebir los humedales se destaca la manera cómo las comunidades locales ven a futuro los mismos, es decir, cuál será su estado en el corto y mediano plazo, a lo que los agentes sociales resaltaron que tienden a desaparecer. En gran parte, debido a la presión que ejerce espacialmente el monocultivo de la caña pues dicha actividad amenaza directamente el futuro de los humedales y la finca tradicional. 
Los agentes entrevistados concluyen que otro elemento clave en la gestión a futuro de los humedales se relaciona con el tema de la propiedad privada, donde actualmente se localizan los humedales, pues las acciones encaminadas en pro de la recuperación de estos ecosistemas deben conciliarse con los propietarios privados, hecho que no siempre ha sido convincente. En palabras de uno de los agentes entrevistados se aprecia lo siguiente:

"El futuro que vemos es que van a acabar con los dos, finca y humedales; porque vea, finca tradicional, la caña la lleva en ruinas. Desaparece finca tradicional, desaparecen humedales, desaparecen humedales, desaparece finca tradicional." (Entrevista agente social, Corregimiento de Villa Paz, 2014).

\section{Espacios vividos}

En esta fase de producción del espacio se destacan elementos asociados a conflictos por el agua de los humedales, que según agentes entrevistados, se hacen evidentes para la década de 1980, cuando los hacendados empezaron a comprar tierras. Este proceso llevó a la expansión de prácticas económicas como la ganadería extensiva, compra de tierras a pequeños agricultores, y a la materialización de obras para drenar humedales, puesto que estos se consideraban como obstáculos para el desarrollo de sus distintas actividades productivas. Dichos cambio se evidencian en la figura 8 y en el retroceso de las coberturas evaluadas (cuadro I). Para inicios del siglo XXI se hace evidente la expansión del monocultivo de caña de azúcar cerca a los humedales de estudio, práctica que empieza a competir espacialmente con áreas destinadas a ganadería, cultivos transitorios y bosques protectores. En ese sentido, surge una de las mayores consecuencias ligadas a la materialización de la caña, y es la construcción de pozos profundos, debido a la necesidad de disponer de fuentes de agua para riego de cultivos. Esta situación ha llevado a reducir los niveles freáticos del suelo, afectando la finca tradicional. En palabras de uno de los agentes entrevistados se aprecia lo siguiente:

"Entonces, el problema está en el crecimiento de la agroindustria, en este momento caña de azúcar y ganadería, dos problemas graves aquí; caña porque los ingenios tapan los canales de alimentación de los humedales y amplían el canal de salida de drenaje para secarlo con su maquinaria; ganadería, que también hace lo mismo para ganarse la tierra, inclusive, ya no tanto para ganadería si no, para apropiarse de nuevos terrenos." (Entrevista agente social, Corregimiento de Quinamayó, 2014).

Los agentes entrevistados resaltan que la regulación del río Cauca a partir de la construcción de la represa Salvajina y obras alternas para la década de 1980, incidieron en la conexión río - humedales - finca tradicional, puesto que la materialización de la represa interrumpió la dinámica natural del principal afluente hídrico, afectando las prácticas de subsistencia de las comunidades locales, el ingreso de agua y alimento a las madreviejas, y favoreciendo los intereses de pocos agentes capitalistas al controlar las frecuentes inundaciones sobre el valle aluvial del río Cauca. 
Con respecto al uso de los humedales, los agentes entrevistados resaltaron actividades relacionadas con: pesca artesanal, la cual ha sido hereda culturalmente entre generaciones; caza de animales silvestres, los cuales proveían parte de la proteína en la dieta alimenticia de las comunidades; actividades de esparcimiento, que incluían labores domésticas cerca al río Cauca; y labores asociadas a la agricultura en función de la finca tradicional. Por otro lado, las de expresiones artísticas de las comunidades locales describen sus prácticas cotidianas a través de la ejecución de danzas y festividades ligadas al río y los humedales, donde el componente unificador ha sido el agua. En tales prácticas se hace alusión a la vida y la muerte, a formas de expresión corporal que reflejan cada uno de los elementos asociados a costumbres culturales, actividades productivas, y su relación sacra con río. En palabras de uno de los agentes se evidencia la forma de vivir estos espacios por parte de las comunidades:

\begin{abstract}
"Esas fiestas expresan la relación con los humedales y el río porque allí se hacen expresiones de danza donde se explica la forma de tirar la atarraya; la manera de sacar el pescado [...] los rituales que se hace allá, que los pescadores realizan para que les vaya bien en la pesca; sí alguno vio una visión, eso se refleja en la fiesta.” (Entrevista Agente Social Corregimiento de Quinamayó, 2014).
\end{abstract}

La actividad de la pesca como espacio vivido es una de las prácticas que genera incertidumbre en relación al uso de los humedales. Los agentes entrevistados concuerdan que actualmente son pocas las personas dedicadas a esta actividad, en comparación a décadas pasadas. Las razones mencionadas son: disminución de peces en los humedales; reducción del área en espejo lagunar; la conexión río - humedal, debido a que los propietarios de predios donde se localizan los humedales modifican los canales de salida y entrada de agua para acelerar los procesos de drenaje. Con respecto a lo anterior, se destacan estrategias asociadas a la introducción de pastos con el fin de proveer alimento al ganado y sedimentar los humedales para apropiarse del área de los mismos (figs. 9 y 10). Culturalmente, las actividades relacionadas con el uso de los humedales se representan a través de la conexión sacra y mística de la naturaleza. Ejemplo de ello, se evidencia en el espacio vivido que describen los agentes entrevistados en el siguiente párrafo:

"En mi época de niño los humedales no eran utilizados si no únicamente para la pesca y había un respeto porque no se pescaba en cualquier momento, ni en cualquier tiempo. Existía una serie de creencias para los pobladores en relación a la pesca y caza en los humedales, lo cual permitía que las poblaciones (de animales) se restablecieran en el tiempo." (Entrevista Agente Social Corregimiento de Villa Paz, 2014).

Actualmente, buena parte de las creencias han desaparecido como resultado de las nuevas formas de producir el espacio, en el cual los roles transmitidos de generación en generación, con respecto a la pesca y actividades agropecuarias, se han ido perdiendo en función de alternativas o actividades productivas como la agroindustria de la caña de azúcar. 


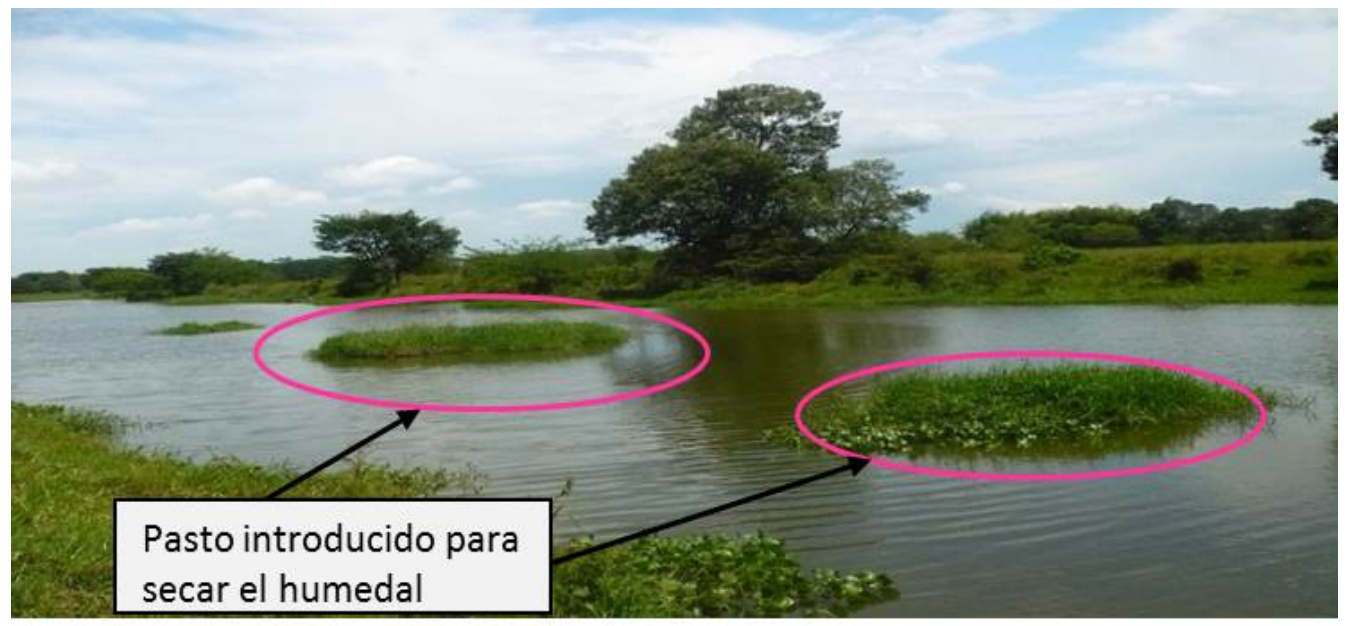

Fig. 9 - Pasto y vegetación acuática flotante, humedal La Guinea (municipio de Jamundí, Colombia). Imágenes a color disponibles online.

Fig. 9 - Grass and floating aquatic vegetation, wetland La Guinea (municipality de Jamundí, Colombia). Colour figure available online.

Fuente: Aguirre \& Perdomo (2015, p. 98)

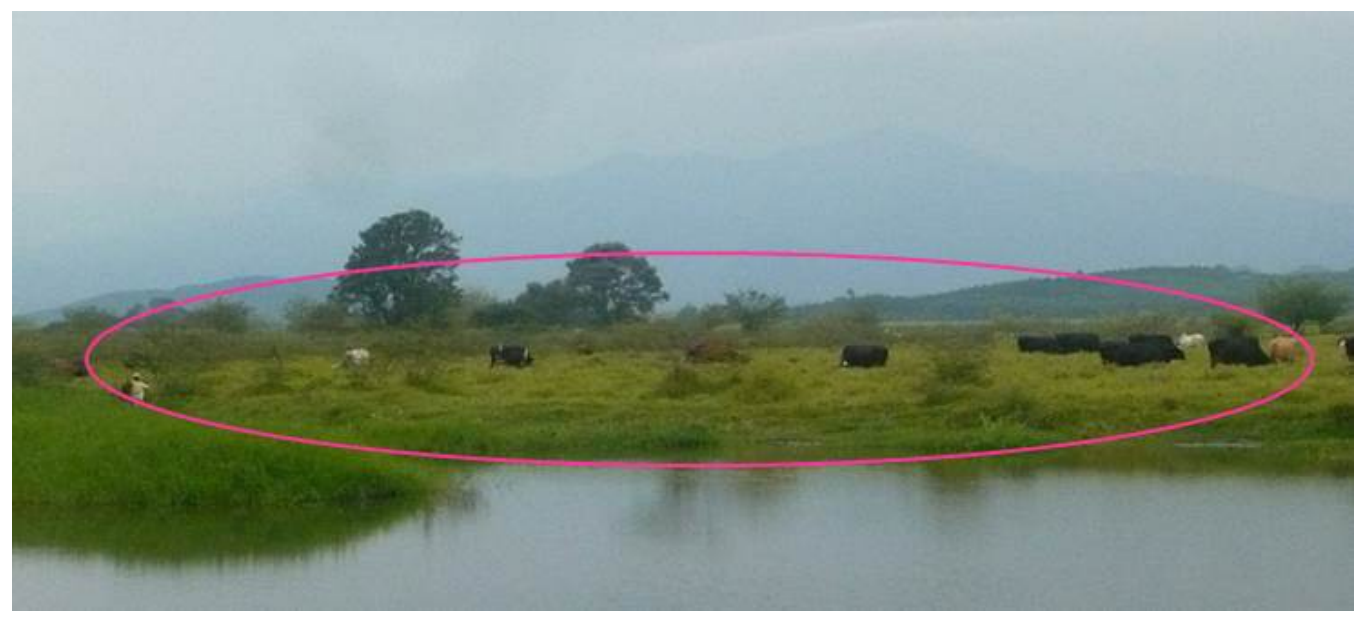

Fig. 10 - Actividad ganadera al interior del humedal Guarinó (municipio de Jamundí, Colombia). Imágenes a color disponibles online.

Fig. 10 - Livestock into the wetland Guarinó ( municipality de Jamundí, Colombia).

Colour figure available online.

Fuente: Aguirre \& Perdomo (2015, p. 98)

Con respecto a lo anterior, los agentes entrevistados mencionaron que hoy en día, uno de los temas que genera mayor incertidumbre en materia social se relaciona con la futura ocupación laboral de las nuevas generaciones, con lo cual, se discute el papel de la formación de agentes sociales en función de la agroindustria versus agentes sociales formados 
a partir de prácticas tradicionales sustentadas en los humedales; práctica que según los agentes entrevistados, ha permitido la subsistencia de una serie de actividades socioeconómicas asociadas a la permanencia de estos ecosistemas en el tiempo. También, se menciona que históricamente se han desarrollado actividades de limpieza en los humedales relacionadas con: extracción de vegetación acuática del espejo de agua; limpieza en canales de entrada y salida del agua de las madreviejas; y prácticas de reforestación por parte de organizaciones locales; además, que las actividades desarrolladas contaban con participación de la Corporación Autónoma Regional del Valle del Cauca (CVC).

A la fecha los humedales de estudio no cuentan con un área de delimitación definida desde la norma, frente a ello las acciones de la CVC como autoridad ambiental se ven frustradas por la intervención de agentes sociales dueños de los predios donde se localizan los humedales ya que estos impiden la ejecución y materialización de tales iniciativas. Actualmente se viene realizando acciones encaminadas con la comunidad para la protección de estos ecosistemas, así como intentar definir áreas para la delimitación de los cuerpos de agua.

\section{CONCLUSIONES}

Es evidente que en los humedales de estudio se presentaron cambios en el paisaje asociados a formas de producción social del espacio entre mediados del siglo XX y principios del siglo XXI propiciados, en mayor medida, por agentes capitalistas a través de sus concepciones espaciales; quienes sustentaron sus improntas bajo el paradigma del desarrollo capitalista a través de prácticas agropecuarias y del agronegocio de la caña de azúcar; dichos cambios reflejan disminución del espejo de agua en humedales y pérdida de coberturas importantes frente a estos ecosistemas en el tiempo, como por ejemplo áreas de bosque y cultivos transitorios.

Entre dichas acciones de producción socioespacial se resalta el papel que han jugado las élites regionales con el auspicio de políticas desarrollistas promovidas por gobiernos de turno, quienes concibieron la planicie aluvial del río Cauca como un área de expansión para el monocultivo de la caña de azúcar, práctica material que sustenta el modelo de desarrollo del agronegocio para la región, desde mediados del siglo XX y consolidado hasta nuestros días con repercusiones ambientales y sociales evidentes en el paisaje del Departamento y en los humedales de estudio. En este contexto, se logra percibir la fase secuencial del espacio concebido por unos pocos agentes sociales, la cual se materializó a través de políticas y estrategias que lograron promulgar, en el tiempo y espacio, la consecución de tales fines económicos y productivos, los cuales finalmente, son transmitidos mediante la interpretación de los espacios vividos, a partir de las narrativas de vida trasmitidas desde las voces de cada uno de los agentes sociales partícipes de la investigación. 
Teóricamente, desde la propuesta de Lefebvre (2013) fue posible avanzar en la identificación de transformaciones socioespaciales ligadas a actividades productivas tales como la ganadería extensiva y la agricultura semitecnificada a través de la implementación de cultivos transitorios, los cuales, para su implementación y materialización, requerían de grandes extensiones de tierra y acceso a fuentes de agua como el río Cauca y sus humedales. Actualmente, los cambios del paisaje transmitidos desde la cartografía y talleres, reflejan un panorama con tendencia hacia la expansión del cultivo de la caña de azúcar, práctica socioespacial que amenaza los intereses de comunidades que por décadas han vivido en relación al agua y los humedales del Sur del municipio de Jamundí. En ese sentido, la mayor preocupación de la comunidad radica en que las nuevas generaciones de jóvenes, herederos y promotores de legados culturales, ligados a una concepción sacra de la naturaleza bajo la triada finca tradicional humedales - río Cauca, se cambie por otra asociada a la actividad agroindustrial de la caña de azúcar.

El enfoque socio crítico de la investigación a partir de los argumentos de Lefebvre (2013) permitieron integrar información cualitativa y cuantitativa en un único marco de referencia metodológico para el desarrollo de este trabajo, así como también, incorporar la constante participación de comunidades presentes en las fases de producción socioespacial de los humedales de estudio con resultados satisfactorios. De esta forma, se logró avanzar en el análisis de las fases de la producción social del espacio, observadas a través de la implementación de talleres, la cartografía, y desde las voces de agentes sociales quienes desde su saber consuetudinario identificaron cada uno de los elementos presentes en las fases de producción socioespacial.

\section{REFERENCIAS BIBLIOGRÁFICAS}

Aguirre, M., \& Perdomo, J. (2015). Producción socioespacial de siete humedales del Valle del Cauca, de mediados del siglo XX a principios del siglo XXI. Santiago de Cali, Colombia: Universidad del Valle.

Bhabha, H. (1994). The location of culture. Buenos Aires: Manantial.

Castañeda, L. (2012). Análisis de las dinámicas espacio-temporales de la cobertura de la tierra en cuatro humedales en el departamento del Valle del Cauca. Santiago de Cali, Colombia: Universidad del Valle.

Corporación Autónoma Regional del Valle del Cauca. (2007). El río Cauca en su valle alto. Un aporte al conocimiento de uno de los ríos más importantes de Colombia. Santiago de Cali, Colombia: Universidad del Valle.
Corporación Autónoma Regional del Valle del Cauca. (2009). Humedales del valle geográfico del río Cauca: Génisis, biodiversidad y conservación. Santiago de Cali, Colombia.

Corporación Autónoma Regional del Valle del Cauca. (2011). Plan de Manejo Ambiental, Humedal Guarinó. Valle del Cauca.

Hernando, A. (2004). El tercer espacio: cruce de culturas en la literatura de frontera. Revista de Literaturas Modernas, 34, 109-120.

Lefebvre, H. (1974) La producción del espacio. (Capitán Swing Libros, S.L, 2013, España. Introducción y traducción por Martínez, E. (2013).

Ministerio del Medio Ambiente. (2002). Política Nacional para Humedales Interiores de Colombia. Bogotá, D.C. 
Perafán, A. (2005). Transformaciones paisajísticas en la zona plana Vallecaucana. En Revista Historia y Espacio, Fascículo 24 (pp. 1-18). Cali, Colombia: Universidad del Valle.

Secretaría de la Convención de Ramsar. (2013). Manual de Convención de Ramsar, Guía a la Convención sobre los Humedales (Ramsar, Irán, 1971 6ª edición).
Soja, E. (Queimada Gráficas, Madrid). (2000). Postmetrópolis: Estudios críticos sobre las ciudades y las regiones. Traducido por Hendel, V., \& Cifuentes, M. (2008) pp, 39, 40, 41.

Zuluaga, F., Mejía, E., Valencia, R., \& Arias, A. (2012). Valle del Cauca: procesos históricos. Cali, Colombia: Manuelita S.A.

i El artículo se presenta como parte de los resultados del proyecto de investigación titulado "Los humedales vallecaucanos: escenario natural de cambios históricos de ocupación y transformación", financiado por la Vicerrectoría de Investigaciones de la Universidad del Valle, 2014.

ii La Convención de Ramsar es uno de los más importantes acuerdos a nivel internacional sobre el medio ambiente. Éste se instauró en la década de 1960 del siglo XX entre países no gubernamentales interesados por el creciente deterioro a escala global de fauna y flora presente en distintos humedales, y su importancia como habita esencial para la conservación de aves. Entre las medidas de cooperación internacional adoptadas por Ramsar se define apoyar activamente a los países miembros en la formulación de políticas e instrumentos que propicien la conservación de humedales en el tiempo. El acuerdo entra en vigencia en 1975, y Colombia se adhiere a él para el año de 1972.

iii La tasa de Cambio porcentual se calculó a partir de la siguiente ecuación $\Delta \mathrm{X}=(\mathrm{X} 2-\mathrm{X} 1) / \mathrm{X} 1{ }^{\star} 100$. Donde: $\mathrm{X} 1$ corresponde al primer año observado y X2, al segundo año por arriba de X1. $\Delta \mathrm{X}$ corresponde al cambio porcentual. Los valores negativos (-) indican pérdida y retroceso de cobertura. Los valores positivos indican un aumento o ganancia de cobertura. Los valores en cero $(0)$ indican que la cobertura aparece por primera vez. Los cuadros con el símbolo $\left(^{*}\right)$ indican que la cobertura no existe aún.

iv Fuenecorobles es una ONG sin ánimo de lucro, organizada por comunidades de base afrodescendientes que se dedican a la protección, conservación y vigilancia de los recursos naturales del sur del Valle del Cauca. Además, cuentan con amplia experiencia en procesos de ordenamiento territorial de cuencas hidrográficas, manejo de residuos sólidos, gestión ambiental de humedales y diagnóstico de factores culturales que transforman el ambiente. 